\title{
Student Performance and Perceptions in a Web-Based Competitive Computer Simulation
}

\author{
Nicole Buzzetto-More and Bryant C. Mitchell \\ University of Maryland Eastern Shore, Princess Anne, MD, USA
}

\author{
nabuzzetto-more@umes.edu; bcmitchell@umes.edu
}

\begin{abstract}
Computer simulations have implications across disciplines and with learners at all levels. By requiring learners to develop and apply knowledge and skills in interactive changing environments, they encourage deeper levels of learning. Additionally, simulations have been shown to be particularly effective at teaching complicated concepts that depend on the ability to understand interrelationships, strategize, make predictions, analyze and evaluate, and engage in multi-faceted decision making.

In order to help students gain a deeper understanding of key business concepts, encourage critical thinking and decision making, foster collaborat ion and critical discourse, and encourage the application of concepts into real world business practices, the University of Maryland Eastern Shore, a minority serving institution, decided in 2004 to introduce a series of compet itive webbased simulations at key junctures throughout the curriculum but focused primarily in the course Strategic Management. The simulation selected covers topics such as Strategy \& T actics, Policy, Production, Accounting, Marketing, Finance, Quality control, Human resources, Leadership, and Teamwork and involves students competing in teams against other teams.
\end{abstract}

In order to assess the effectiveness of the simulation, a research protocol was introduced that included the administration of student surveys as well as the collection of performance data. The findings indicatethat students overwhelmingly felt that the simulation helped them understand the application of key concepts and learn the decision making process that occurs in professional business practice.

The examination of student performance dat a gathered in this study, with consideration given to the strong levels of student satisfaction, encouraged the authors to postulate based on the high success rates of this student population, which traditionally underperforms in more traditional mode of assessments, that simulations may serve as an equalizer that offers all students, from low to high achievers, an opportunity to succeed and that competitive web-based simulations enhance the overall educational and personal development experiences of minority students enrolled in higher education business programs.

Material published as part of this publication, either on-line or in print, is copyrighted by the Informing Science Institute. Permission to make digital or paper copy of part or all of these works for personal or classroomuse is granted without fee provided that the copies are not made or distributed for profit or commercial advantage AND that copies 1 ) bear this notice in full and 2) give the full citation on the first page. It is permissible to abstract these works so long as credit is given. To copy in all other cases or to republish or to post on a server or to redistribute to lists requires specific permission and payment ofa fee. Contact Publisher@,InformingScience.org to request redistribution permission.
Keywords: Simulations, project-based learning, capstone, minority leamers

\section{Background}

The University of Maryland Eastern Shore (UMES) is a Historically Black University and member of the University System of Maryland, which primarily serves first generation, academically under-prepared, low income, and minor- 
ity learners (Buzzetto-More \& Ukoha, 2009). The student population is approximately 4200, reporting a student body that is approximately $78 \%$ African-American, 9.6\% white, $1.4 \%$ Hispanic, and $11 \%$ international, primarily coming from the continent of Africa or from the Caribbean region. The gender distribution of the University is $64 \%$ female and $36 \%$ male. The average SAT score of the 2007 freshmen class was 817, the current freshmen to sophomore retention rate is $64 \%$, and the graduation rate is $41 \%$. The average GP A of the fall 2007 freshmen class was a 2.75 and the acceptance rate for applying students is $79 \%$.

As a result of the liberal acceptance policy of the inst itution, UMES attracts a high proportion of first generation and/or under-prepared students. The Department of Business Management and Accounting (DBMA) is one of the largest departments on campus. The Department has approximately 420 majors, offering programs that include Business Administration, Accounting, Business Education, Finance, and Marketing. The freshmen admission standards for students seeking to enter the Department are higher than those required by the larger university, with a requisite combined math and verbal SAT score of 850 and a GPA of 2.8. Students who are not admitted as freshmen are allowed to transfer into the Department following the completion of 30 academic credits and with a GPA of a 2.8 or better having earned no grades below a C.

Willie, Reddick, and Brown (2005) explained that throughout their history Historically Black Colleges and Universities (HBCUs) have focused on opening doors closed to students because of their scores on standardized tests by providing remedial, mentoring, and supportive services to students whose academic backgrounds reflect low achievement, and that, today, the mission of contemporary HBCUs remains the same. They explained that the goal of opening new opport unities while rectifying deficits of the past and preparing students for professional and academic success remains at the fore. Concurrent with the mission of HBCUs to open doors for students by creating opport unities for students to succeed is the implementation of student centered learning initiatives such as electronic portfolios and simulations (Buzzetto-More, 2008).

In order to help students gain a deeper understanding of key business concepts, encourage critical thinking and decision making, foster collaboration and critical discourse, and encourage the application of concepts into real world business practices, the University of Maryland Eastern Shore decided in 2004 to introduce a series of competitive web-based simulations at key junctures throughout the curriculum but focused primarily in the course Strategic Management. The simulation selected was the Capstone ${ }^{\circledR}$ Business Simulation. The Capstone ${ }^{\circledR}$ simulation covers such topics as Strategy \& Tactics, Policy, Production, Accounting, Marketing, Finance, Quality control, Human resources, Leadership, and T eamwork. Students compete in teams against other teams and the system supports individual and group decision making, essay assignment responses, team and class bulletin board messages and email, solo rehearsal exercises, a peer evaluation system with results reporting across a range of behaviors and abilities, decision results, aut omated round analysis, student tracking, national and institutional group rankings, and quiz results. It also works in conjunction with a comprehensive web based examination that is aligned with simulation activities and that has been recognized by the American Association of Colleges and Schools of Business International. The program is hosted online by the Capsim Company and students pay for a user license.

The Capstone Simulation has been adopted by over 500 schools worldwide, as well as by a number of large corporate entities, allowing students to compete against a wide range of groups. For students attending a minority serving institution, this is the first time that many of these students will have the opport unity to interact with, as well as compete against, Fortune 500 executives as well as fellow students attending top tier majority serving institutions. It is believed that success in real world-oriented business simulations results in the increase in the decision making and business acumen confidence of students. Furthermore, the DBMA believes that the usage of 
competitive simulations as a student leaming and assessment regime complements the academic and professional needs of students in harmony with the academic mission of the instit ution.

\section{Literature Review}

Numerous studies have linked e-learning to critical thinking; for example, a study of 300 recent MBA graduates conducted at the University of Wisconsin-Whit ewater found that online learning encourages high level reflective thinking (Drago, 2004).

Experts suggest that student work should be authentic or based on the real world (Wiggins, 1990). Frequently known as project based learning, it is a form of instruction where students are immersed in challenging learning situations that are anchored in real world simulations (Page, 2006). According to Page, project based learning can support critical thinking, multilayered decision making, goal setting, problem solving, and collaboration. As a result, many institutions are anchoring their assessment activities into meaningful scenarios so that students are being assessed on their abilities to apply learning to realistic situations.

Computer simulations are a form of project based learning that requires learners to discover and apply learned skills in interactive changing environments that mimic real-world situations (Berge, 2002), encouraging critical thinking and discovery learning (Buzzetto-More, 2008). They have been shown to foster lifelong learning, support learning at all levels from K-12 education to professional development training, help individuals build collaboration skills, and help learners develop deeper understandings of concepts (Cherry, 1999).

According to Kolb (1984) the authentic and complex learning environments supported by simulations encourage relationships between concepts and application of concepts, as well as the view of topics from multiple perspectives. Kolb explains that simulations give learners the opportunities to face real-life problems enabling them to learn by doing (Kolb, 1984).

Simulations are certainly not new to the educational arena; however, as a result of research validation and technological developments and with a greater push towards performance based assessment, simulation usage has been growing exponentially (Buzzetto-More, Werner, \& Martinez, 2008). Simulations have been shown to help learners understand complex business functions while building collaboration skills (Laineama \& Lainema, 2007) as they allow students to benefit from experiential learning in a manner that is self motivated and self directed. They have been found effective at enhancing student interest and motivation by making learning more vivid and realistic (Limniou, Papadopoulos, \& Roberts, 2008). While the benefits are numerous, AriasAranda (2007) explained that simulations have two major benefits: on the one hand, they offer a teaching framework based on competition motivated decision making towards a goal of winning, and, on the other hand, learning occurs through a feedback and response framework.

Research by Kerka (2001) found teachers who utilize simulations and project-based learning have more students who are able to synthesis many disciplines of knowledge in a single situation, and the findings of a study by Astleitner (2002) explained that critical thinking and higher order operations significantly increase when students learn through simulations. Analyzing hypothesis/positions, reflecting on judgments, and evaluating results are key elements of both higher order thinking and simulations (Astleitner, 2002).

Strat egic management is a complicated area of study that is based on the understanding of interrelationships between strategic decisions of the different functional areas of a firm (Mankins, 2004). Theoretical approaches to the subject matter have been shown to be limited, as students are shown strategic decision-making as a static process (MacKay \& McKiernan, 2004). While the benefits of active learning are established, most higher education strat egic, production, and/or operations management courses remain lecture based, exposing students to abstracted concepts. 
Case studies have been presented as the remedy to this abstraction as students are exposed to applied decision making; however, cases are criticized for their static nature (Mitchell, 2004).

In a 2007 study, Arias-Aranda examined the effectiveness of a strategic management simulation in business courses offered at a university in Slovakia. The results of the study revealed high levels of satisfaction and motivation amongst students. Arias-Aranda explained that the simulation positively influenced the practice of learning while building the strat egic thinking, decisionmaking, and management skills of learners.

In a study that examined the impact of simulation based education on the teaching of supply chain concepts, Siddiqui, Khan, and Akhtar (2008) found high levels of learning effectiveness. Based on the data analyzed, the authors concluded that simulations offer student centered learning methodologies that are effective at encouraging critical thinking and multi-layered decision making.

Lainema and Nurmi (2006), who applied a computer simulation in a real-world business organization, cited the importance of dynamicity and interactivity as crucial to success. Further, they concluded that simulations are able to authentically represent the complex, causal, time-bound nature of business organizations.

The Northeastern University College of Business Administration (2008) has committed it self to the incorporation of simulations in their curriculum by requiring undergraduates to compete in a business simulation in their capst one course. During the simulation, students are required to work collaboratively in teams while int egrating several key concepts learned throughout their business studies. Done during a three week period, it is designed to help draw linkages between business concepts, business enterprises, and concepts and their applications. T eams of five compete against each other during a number of rounds.

Examining the role of simulations in continuing professional development, Wall and Ahmed (2008) examined the effectiveness of the introduction of a simulation in the professional development training of construction professionals in Ireland. The findings from the study indicated that simulations are effective at the delivery of learning with adult learners as well as with encouraging lifelong learning. They warned educators, however, that simulation usage requires careful planning, the establishment of milestones, and careful management.

Lainema and Lainema (2007) found that simulations support the overall understanding of the functioning of business organizations. They identified key characteristics that should be considered integral to effective simulations:

1) Learner empowerment through autonomy

2) Learning by doing

3) Task authenticity

4) Intensity of thetask

5) Complexity

6) Collective experiencethrough team achievement

They applied their criteriato a simulation called RealGame, which mimicked the operations and decision making of a manufact uring company and required students to deal with such issues as competition, research and development, sales, pricing, delivery speed, and term of payment, production, workforce capacity, raw materials acquisition, marketing, inventory management, deliveries, and funding. Following an examination they found that participants considered the complexity and challenge a motivating factor and that overall users considered the simulation to be a positive experience that enhanced their learning. 
Even Harvard Business School has embraced simulations with the release of the commercially available Universal Rental Car Pricing Simulation, the first in a line of new Online Simulations to be introduced by this renowned institution. They explain that simulations are designed to make the MBA experience of students more fun, particularly with generations of learners who have an affinity for technology usage (Harvard Business School Publishing, 2008.

\section{Methodology}

Senior business majors attending the University of Maryland Eastern Shore enrolled in undergraduate courses in production management and strategic management completed six rounds of the Capstone Business Simulation wherethey were evaluated based on profit, stock price, retum on equity, return on sales, return on assets, and asset takeover. Students competed in collaborative teams against teams from other universities as well as against business professionals. Additionally, students were required to participate in one round of the simulation on an individual basis. Throughout the experience, students completed a process diary where they reflected upon their decisions and processes, Additional assessment measures included peer assessment and results from the comprehensive exam offered in conjunction with the simulation.

In order to assess the effectiveness of the student simulation initiative, a research protocol was introduced that included the administration of student surveys as well as the collection of performance data. The survey was administered via an online survey tool following completion of the simulation. Students were personally sent an invitation via email and, while their responses were anonymous, they did receive academic credit for visiting the survey website. The survey included a mixture of multiple choice and five point Likert scaled questions. The frequency distribution as well as descriptive statistics was analyzed. Additionally, a number of cross tabulations were run. The performance data collected included group and individual simulation scores, rankings, percentile distribution, and alignment with GP As.

\section{Data Analysis}

One hundred and thirty-eight students completed the survey. Fifty-one percent of the respondents who completed the survey were female and $49 \%$ were male, which is representat ive of the University's larger student body. Two and a half percent of the respondents were sophomores, $11 \%$ junior, and $86.5 \%$ senior. Thirty-seven percent of the respondents were between the ages of 17 $21,58.4 \%$ were between the ages of $22-25$, and $3.9 \%$ were 31 or older.

Prior experience with simulations was examined and, according to the participants, $65.8 \%$ had prior experience completing a computer simulation with $34.8 \%$ saying that this was their first experience. With respect to simulations in their business courses, $45 \%$ said that this was their first simulation in a business course with 55\% saying that they had prior experience(s).

Computer ownership was examined; $85 \%$ reported that they own their own computer and $15 \%$ said that they do not personally own a computer, which was lower than the $97.8 \%$ rate of ownership that was reported by Salaway, Katz, and Caruso (2006). Additionally, 92\% said that they have internet access at their residence; however, the type of internet connection varied with $18.7 \%$ responding $56 \mathrm{~K}$ modem, $20.6 \%$ high speed dial up, $1.9 \%$ satellite, $41 \%$ through a cable provider, and $18 \%$ being not sure.

When asked where they were most likely to access the simulation, $88 \%$ said at school with $4.2 \%$ responding at work, and $7.6 \%$ saying at home. Students were asked how many hours they spent per week working on the simulation with $3.4 \%$ saying none, $30.5 \% 1-2$ hours, $40.7 \% 3-5$ hours, $12.7 \% 6-8,9.3 \% 9-11$ hours, $2.5 \% 12-15$ hours, and $<1 \% 16-21$ hours. 
Familiarity with collaborative learning was common. Most students had numerous experiences with group work (59.6\%) with $23.7 \%$ saying 3-5 experiences, $13.2 \%$ saying $1-2$ experiences, and only $3.5 \%$ saying no prior experiences.

Students largely agreed (49.2\%) that participation in the computer simulation increased their confidence in their ability to make key management decisions, represented in Figure 1. These findings are similar to what was reported by Kolb (1984) more than 25 years ago.

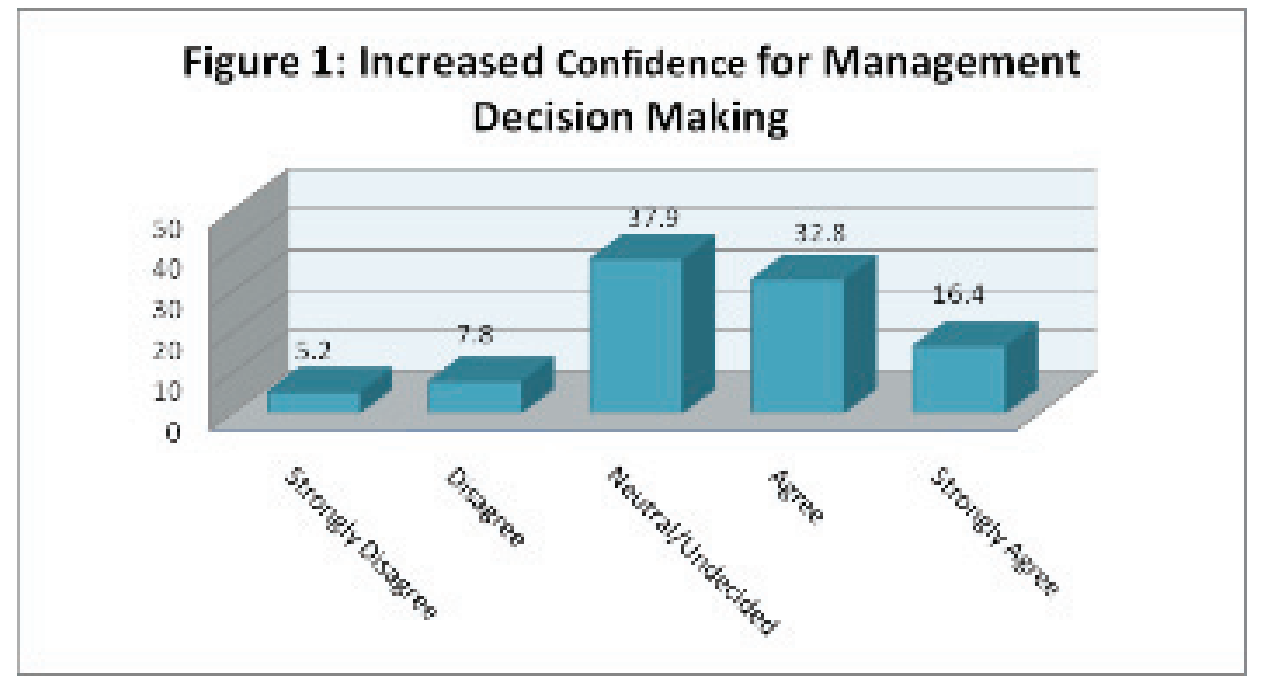

While the literature has indicated the effectiveness of simulations (Arias-Aranda, 2007; Laineama \& Lainema, 2007), the perception of students with respect to value added is largely missing from the literature. According to the findings, students overwhelming considered the simulation to be a valuable learning experience ( $73.3 \%$ agree/strongly agree), represented in Figure 2. These findings compliment the findings of Laineama and Lainema (2007) whose research showed that students perceive simulations as enhancements to the learning experience.

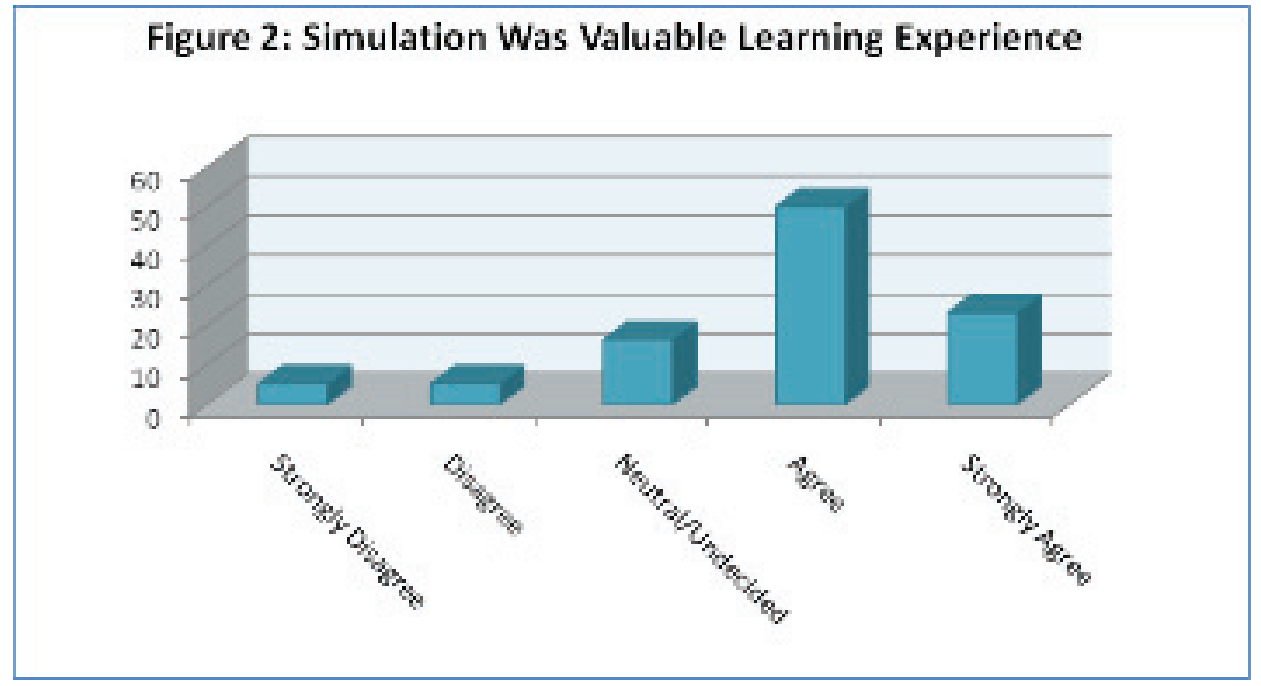

Competitive simulations are increasing in popularity and are designed to provide additional performance incentivethrough competitive challenge and increased stakes (Buzzetto-More, Werner, \& Martinez, 2008). Further, competitive simulations provide students with exposure to a greater range of possibilities, results, and processes (Buzzetto-More, 2007). In order to examine whether the competitive nature of the simulation added value, the students were asked whether they liked 
that they were able to compete with industry professionals, their fellow students, and other university teams. The majority of respondents $(72.2 \%)$ agree/strongly agreed to the stat ement.

The students responded that the simulation increased their understanding of course concepts $(69 \%$ agree/strongly agree), represented in Figure 3. These findings are in agreement with what has been reported by Siddiqui, Khan, and Akhtar (2008) who also found that simulations are highly effective at helping students learn course concepts.

\section{Figure 3: The simulation helped me better understand key business/course concepts.}

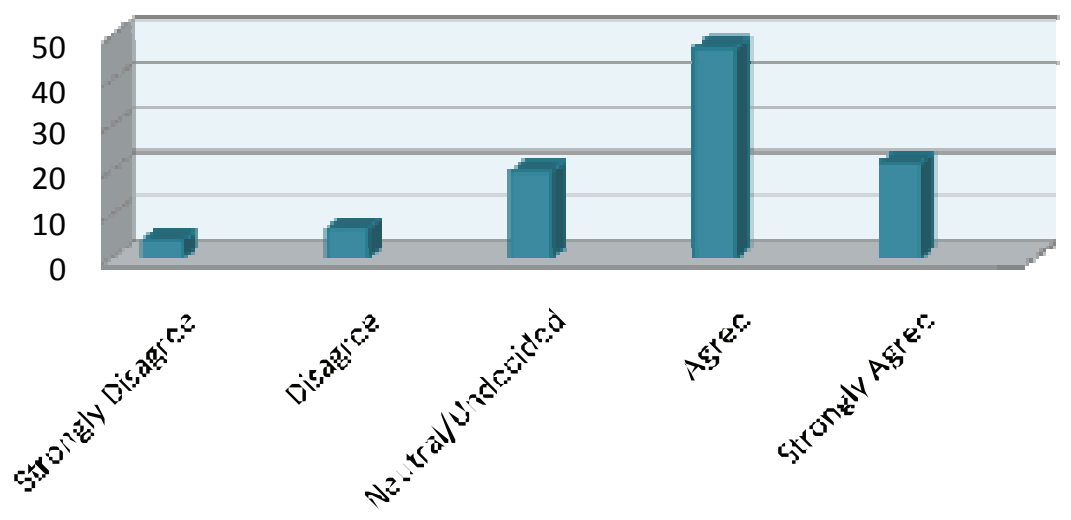

Most students agreed that the support offered was adequate (67.3\%) and that enough time was given to complete the simulation $(72.1 \%)$. The fact that the simulation was factored into their course grade tended to impact participation, with most students $(61.4 \%)$ agreeing/strongly agreeing that their participation was greater because they were being graded. At the same time, few students felt that simulation performance should be factored into their course grade.

Most students (59.6\%) agreed/strongly agreed that they were pleased with their performance on the simulation. Additionally, the simulations were found to make classes more fun $(62.6 \%$ agreed/strongly agreed).

Students largely agreed that they would like to see more simulations in their business courses (55.9\% agree/ strongly agree) believing that they allow students to see how course concepts are applied in real world business practices (77.3\% agreement/strong agreement), represented in Figure 4. 


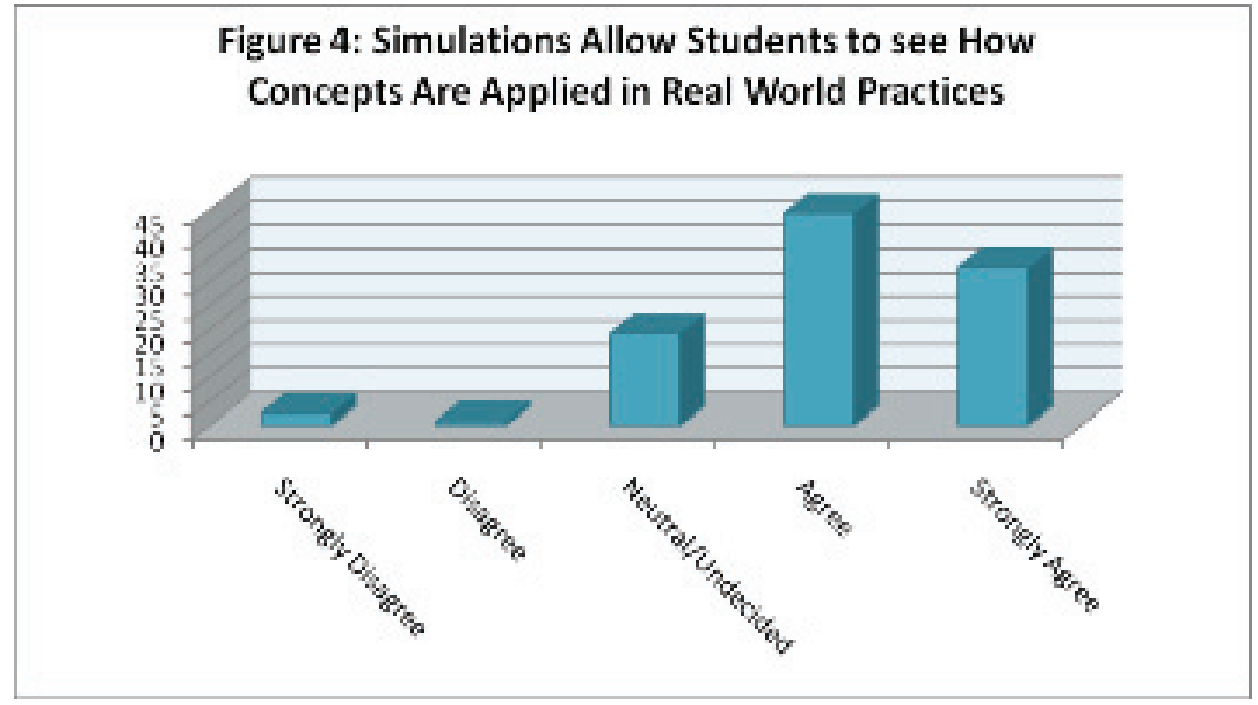

Students responded that simulations help learners build professional skills $(62.1 \%$ agree/strongly agree) (see Figure 5) and better understand the decision making process that occurs in professional business practice (66.7\%). These opinions are similar to what has been reported by Limniou, Papadopoulos, and Roberts (2007) and Astleitner (2002).

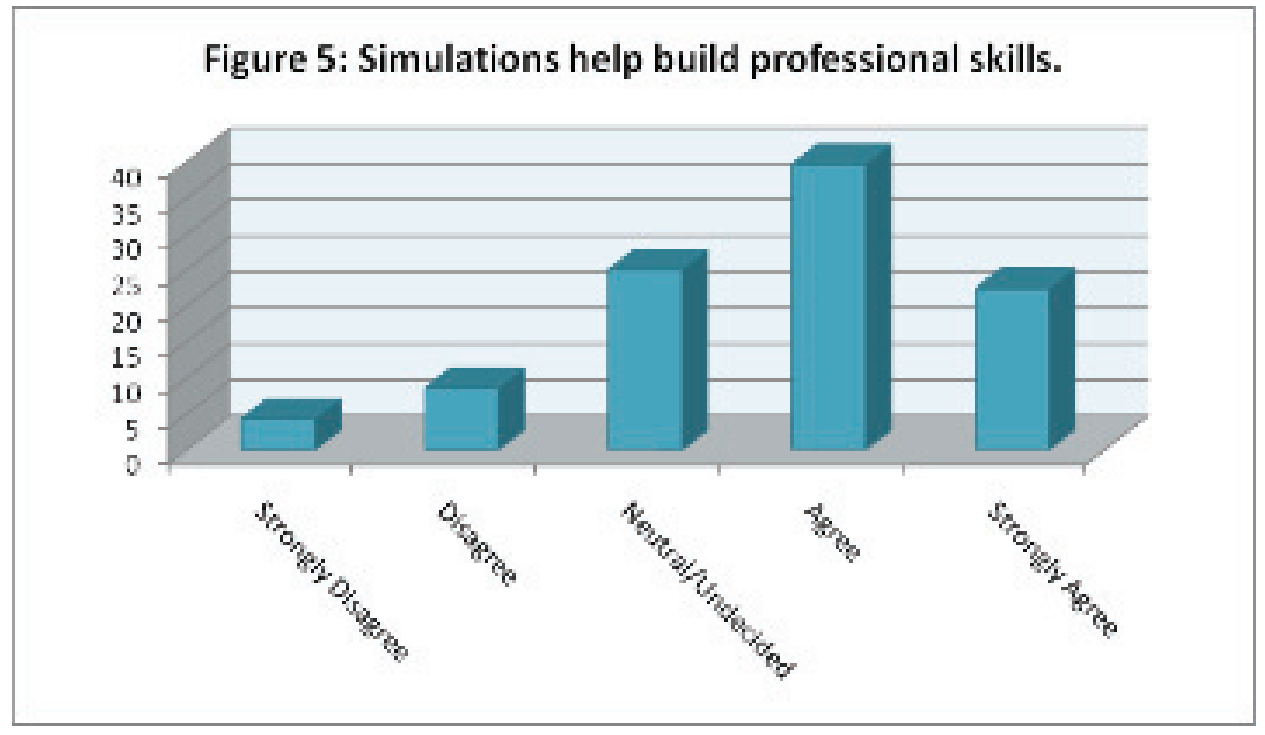

A series of questions looked at students' views of group work, and 53\% said that enjoy working in groups with (70\%) saying that group projects help prepare students to be able to work in professional work groups in the future. Additionally, most students $(58.8 \%)$ said that when working in groups they usually take a leadership position. Finally, when asked whether they plan to own their own business in the future $57.6 \%$ said yes, $28.8 \%$ were undecided and $13.5 \%$ said "No".

Descriptive Statistics were analyzed and sorted from highest to lowest based on mean. The results are depicted in Table 1. A review of the descriptive statistics clearly illustrates high levels of reported student satisfaction. 


\begin{tabular}{|l|r|r|}
\hline \multicolumn{1}{|c|}{ Table 1: Descriptive Statistics } & Me an & $\begin{array}{c}\text { Std. } \\
\text { De viation }\end{array}$ \\
\hline $\begin{array}{l}\text { Simulations allow students to see how course concepts are } \\
\text { applied in real world business practice. }\end{array}$ & 4.04 & 0.892 \\
\hline Simulations provide valuable real-world experiences. & 3.91 & 0.894 \\
\hline $\begin{array}{l}\text { Group projects help prepare students to be able to work in } \\
\text { professional work groups in the future. }\end{array}$ & 3.88 & 0.931 \\
\hline $\begin{array}{l}\text { I liked that I was able to compete with industry profession- } \\
\text { als, my fellow students, and other university teams. }\end{array}$ & 3.82 & 0.979 \\
\hline The simulation was a valuable learning experience. & 3.81 & 1.021 \\
\hline $\begin{array}{l}\text { The computer simulation helped me better understand the } \\
\text { decision making process that occurs in professional business } \\
\text { practice. }\end{array}$ & 3.79 & 0.972 \\
\hline $\begin{array}{l}\text { The computer simulation helped me understand key busi- } \\
\text { ness/course concepts. }\end{array}$ & 3.75 & 1.012 \\
\hline Computer simulations can make class more fun. & 3.74 & 1.044 \\
\hline I am pleased with my performance on the simulation. & 3.72 & 1.031 \\
\hline $\begin{array}{l}\text { My participation in the simulation was greater because my } \\
\text { participation/performance was being graded. }\end{array}$ & 3.68 & 0.886 \\
\hline Simulations help students build professional skills. & 3.67 & 1.053 \\
\hline I enjoyed the computer simulation. & 3.53 & 1.099 \\
\hline $\begin{array}{l}\text { I enjoy working in groups. } \\
\text { my abilities to make key managem ent decisions. } \\
\text { be factored into course grades. }\end{array}$ & 3.49 & 1.127 \\
\hline I would like to do more simulations in my business courses. & 3.48 & 1.16 \\
\hline
\end{tabular}

\section{Cross-tabulations and ANOVA}

A number of Cross-tabulations were run, and when gender was considered men were more likely to be in agreement to the statement "I enjoyed the computer simulation" as well as believe that the simulation helped them better understand course concepts. At the same time, the genders were equally as likely to agree that the simulation was a valuable learning experience.

Students who were first time simulation participants were slightly more likely to respond that they enjoyed the computer simulation, but when it can to the belief that the computer simulation 
helped them understand key concepts or that the simulation was a valuable learning experience prior experience and/or inexperience were not a factor.

The amount of experience a student had with group work had no relevance on whether the student enjoyed the computer simulation or thought it was a valuable learning experience, but it did slightly impact the beliefthat the computer simulation helped them understand key concepts with students with greater levels of experience increasing in agreement.

Students who enjoy working in groups are more likely to have enjoyed the computer simulation, felt that it was a valuable learning experience, believed that it would help them work in professional work groups in the future, and wanted to see more simulations in their business courses. Additionally, whether or not a student said that they plan on owning their own business in the future had no bearing on their enjoyment or belief that the simulation was a valuable learning experience.

\section{Student Performance Data}

In order to examine student performance two terms were examined (Spring and Fall in 2008). During the analysis, the overall performance of the three participat ing teams across all six rounds was considered and compared to the performances of two computer generated teams as well as all participating teams. Rankings are configured by the system based on scores achieved for each round. Table 2 represents the cumulative and percentile rankings achieved following completion of all rounds.

Based on the data, one can clearly tell that the student teams consistently outperformed the computer generated teams and scored well against the 4,548 teams that competed. Overall, the analysis of the student data shows that the participants performed successfully in the simulation besting many teams from traditional majority serving institutions.

We believe that the positive comparative performance (which is shared with students throughout the process) helps to increase the confidence of these primarily low income, first generation minority college students who are otherwise availed few opport unities to interact with, let alone compete against, students from top ranked majority inst it utions. Furthermore, it provides these students tangible evidence of their business acumen which can be shared with prospective employers.

\begin{tabular}{|lc|c|}
\hline \multicolumn{1}{|c}{ Table 2: Rankings } & Cum Ranking & Rank Percentile \\
Team Name & 722 & 85 \\
\hline Andrews & 1429 & 69 \\
\hline Baldwin & 2752 & 40 \\
\hline Chester & 3260 & 28 \\
\hline Digby (Computer Team) & 4403 & 3 \\
\hline Erie (Computer Team) & $\mathbf{4 5 4 8}$ \\
\hline Total Participating Teams & \\
\hline
\end{tabular}

Following the completion of the team simulation, 18 students completed round one of the simulation on an individual basis where they competed against and were compared to the results of the computer running the simulation independently. The computer generated score was given a point value of 100 and students were appointed their score in relation to their points above or below the computer. An examination of the scores (indicated in Table 3) shows that 13 of the participating students out-performed the computer (indicated in grey) while 5 students under-performed the computer (indicated in black). Student grade point averages (G.P.A.) were considered and com- 
pared against student performance in order to determine whether G.P.A was an indicator of a student's likely performance on the simulation. This information is also illustrated in Table 3 where the table is sorted based on G.P.A. in ascending order. G.P.A.s at the institution under consideration are based on a 4 point scale where $A=4, B=3, C=2, D=1,<1=F$. To view the G.P.A.s in relation to individual simulation scores they were aligned side by side.

When G.P.A. was compared to simulation score, it was clear that a greater number of students with G.P.A. s of $<3.0$ underperformed the computer; however, when the information was charted in order to determine whether a trend existed (depicted in Figure 6) no clear trend was illustrated, which may indicate that simulations offer all students from low achievers to high achievers an opportunity to succeed, serving as an effective educational equalizer.

\begin{tabular}{|c|c|}
\hline $\begin{array}{c}\text { Table 3: G.P.A } \\
\text { S IMS core }\end{array}$ & Grade Point Average \\
\hline 116.00 & 1.971 \\
\hline 111.20 & 2.537 \\
\hline 116.30 & 2.558 \\
\hline 50.00 & 2.595 \\
\hline 50.00 & 2.674 \\
\hline 105.90 & 2.781 \\
\hline 82.50 & 2.875 \\
\hline 50.00 & 2.889 \\
\hline 123.40 & 2.975 \\
\hline 109.00 & 3.023 \\
\hline 113.40 & 3.035 \\
\hline 123.80 & 3.143 \\
\hline 50.00 & 3.411 \\
\hline 117.40 & 3.669 \\
\hline 119.70 & 3.67 \\
\hline 107.40 & 3.682 \\
\hline 141.80 & 3.759 \\
\hline 115.50 & 3.840 \\
\hline
\end{tabular}

Student tracking continued in the fall of 2008. 16 teams from the University of Maryland Eastern Shore participated against 12,485 teams representing a wide range of universities and colleges from across the globe as well as including a number of teams from Fortune 500 companies. Among the list of participat ing teams were teams from:

American University

Cornell University

General Electric

Georgetown University

Georgia Tech

Harvard

HCL T echnologies

HEG Geneva
Indiana University

Idaho State University

Rutgers University

Microsoft Corporation

Stanford University

Ohio State University

Tulane

the Citadel
UMass

University of Maryland

University of Maryland

Eastern Shore

University of PA

University of Wisconsin

University of Notre Dame

Villanova University. 
The overall rankings were examined and percentiles established. The data clearly illustrate the high levels of performance of the student teams. Half of the participating teams from the University of Maryland Eastern Shore scored within the top $10 \%\left(>90^{\text {th }}\right.$ percentile). One quarter, or 4 teams, scored within the top $20 \%\left(>80^{\text {th }}\right.$ percentile). The overall rankings are noted in Table 4 where top $10 \%$ teams are marked in grey and top $20 \%$ teams in black.

\begin{tabular}{|l|r|}
\hline \multicolumn{2}{|c|}{ Table 4: FALL 2008 } \\
\hline TEAM & PERCENTILE \\
\hline Team 1 & 98 \\
\hline Team 2 & 69 \\
\hline Team 3 & 75 \\
\hline Team 4 & 87 \\
\hline Team 5 & 90 \\
\hline Team 6 & 98 \\
\hline Team 7 & 81 \\
\hline Team 8 & 90 \\
\hline Team 9 & 81 \\
\hline Team 10 & 25 \\
\hline Team 11 & 72 \\
\hline Team 12 & 84 \\
\hline Team 13 & 99.3 \\
\hline Team 14 & 96.2 \\
\hline Team 15 & 96.1 \\
\hline Team 16 & 98.6 \\
\hline
\end{tabular}

The simulation is based on a series of rounds and a number of components which include: Net Profits, Stock Price, Return on Equity, Return on Sales, Return on Assets, and Asset Turnover. Most believe that each component is not of equal value with most instruct ors feeling that stock price, return on equity, return on sales, and return on assets are the most relevant. As a result, team performance on individual components was examined and expressed in Table 5.

The data represented in Table 5 include actual numeric ranking as well as rank percentile and instances where scores are within the top $10 \%$ are shaded. According to the data, the teams were successful most successful in net profits, stock price, return on equity, return on sales, and return on assets. With respect to net profits and stock price 7 of the 16 teams were in the top $10 \%$; that number went up to 8 with respect to return on equity, 12 for return on sales, and 11 for return on assets. The least successful area was asset turnover where 3 teams scored in the top $10 \%$. Additionally, the data show that on 18 occasions teams scored within the top 100 with three instances where the scores were in the top 10. 

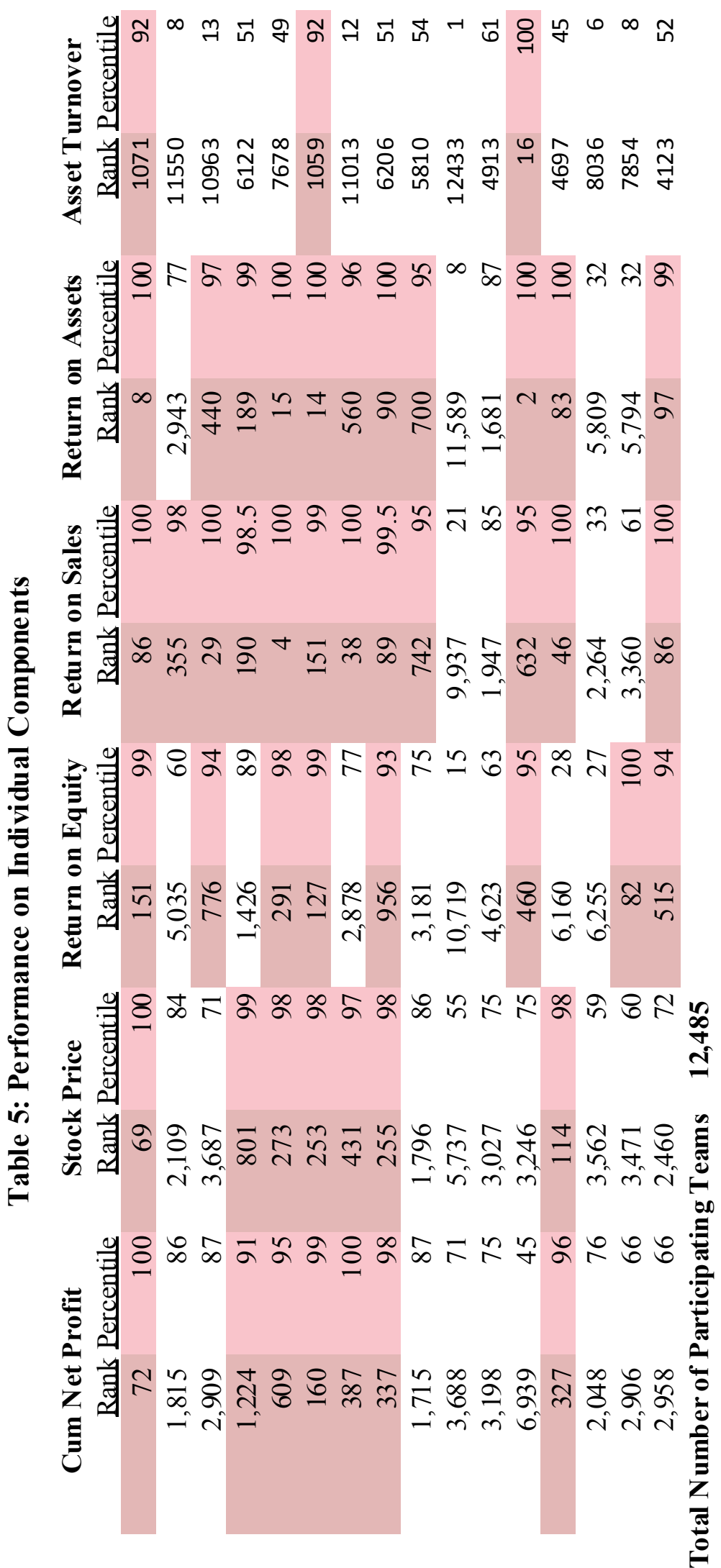

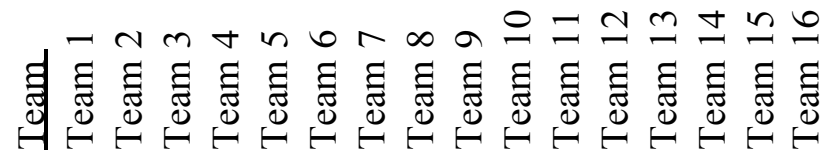


Overall, the student scores are a strong indicat or of the high success rates of the students under consideration. The teams representing the University of Maryland Eastern Shore consistently outperform teams from top tier academic institutions as well as professionals from Fortune 500 companies.

The question as to what strategies the students may or may not be employing arose. The University of Maryland Eastern Shore's Department of Business, Management, and Accounting emphasizes supply chain management and lean production. This knowledge, while commonly available to instruct ors across the globe, may not be as widely emphasized in college curricula that teach business using more traditional approaches. As a result, the Department considered that the strat egies taught in the curriculum when applied to the simulation may encourage positive performance on the simulation.

A comprehensive exam of concepts covered in the simulation has been developed by the Capsim Corporation and has been approved as an assessment measure by the American Association of Colleges and Schools of Business International. In the Fall of 2008 this exam was administered at the University of Maryland Eastern Shore. The student scores have been collected and are currently under analysis.

\section{Limitations}

While this study has provided relevant information regarding students' perceptions of, as well as success with, electronic simulations and focused on a population that is all too often ignored in the literature; the greatest limitation of this study is that data was not available to examine whether simulation participation did or did not directly impact student learning and understanding of key concepts. This limitation is being addressed with current data.

\section{Simulation Implementation}

Encouraged by the successful performance of students as well as the positive survey results, the authors decided to develop an implementation model. The model under consideration is comprised of three stages.

Stage one is Orientation. It involves: the articulation of learning goals, performance outcomes \& indicators; the communications of expectations for individual and/or group performance; the distribution of guides and/or guidelines for decision making and acting; and the introduction to the simulation (background, problem, task, roles, etc). Stage one cannot be rushed and provides the foundation for later success. A frequent failure of simulations is an inadequate orientation, a lack of clear goals and expectations, and too few guides and/or resources.

Stage two is Action. It involves students being required to gather information to engender decisions. which increase the students' activity and engagement levels. It is immediately followed by action by the student(s) with documented decision making. Because simulations are dynamic and interactive, student actions have immediate results that require reaction. So that students are engaging in self-reflection, students should be required to document their progress and author reflections in their process diary.

Stage three is Evaluation. It involves the instructor engaging the students in periodic discussion sessions where thoughtful debate, analysis and evaluation, and critical discourse occur. In order to evaluate performance, the application of multiple assessment regimes should be applied and may include: simulation performance, peer assessment, process diaries, and content examinations. In order to ensure that the knowledge and skills developed persist, closing activities with a wrap up session must be included.

The graphic organizer of the model is represented by Figure 7. 
Figure 7: Simulation Implementation Model

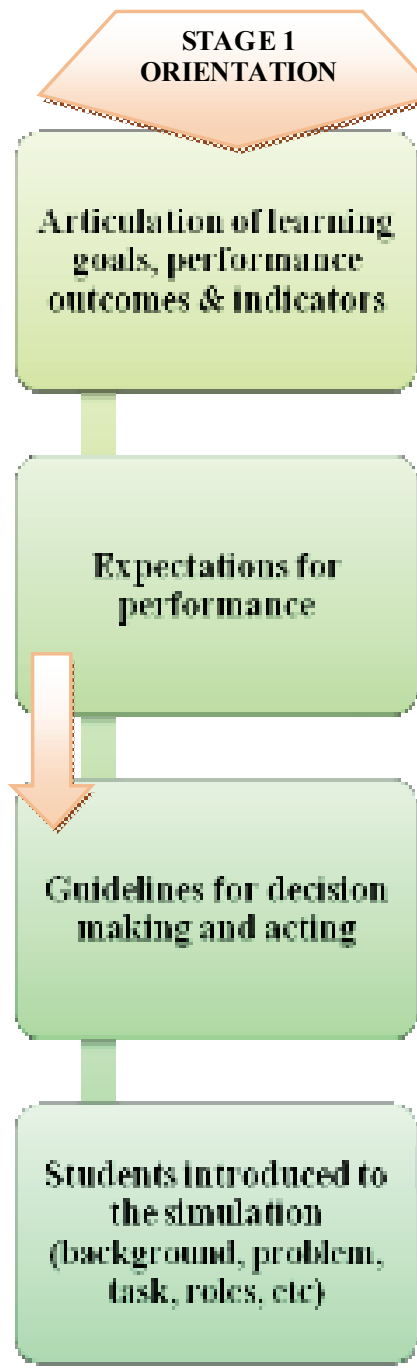

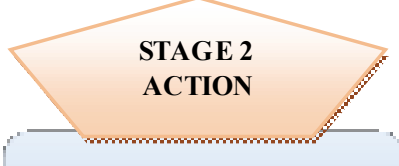

Intermalization by student with reflection writing through a process disy

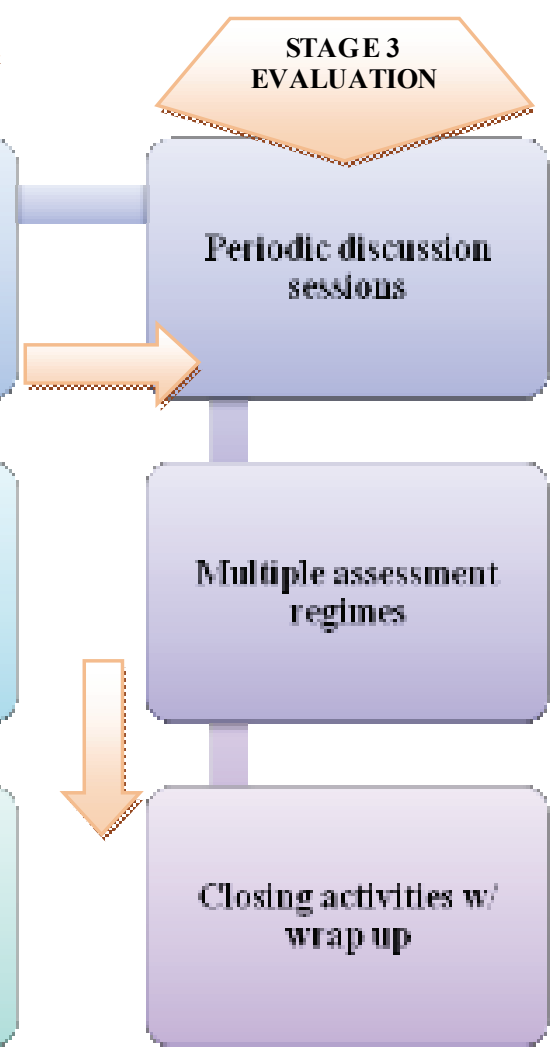

\section{Summary and Future Research}

The students participating in this study overwhelmingly felt that simulations help learners to see how course concepts are applied in real world business practices, serve as valuable learning experiences, and help learners understand the decision making process that occurs in business practice. Most students said that simulations make leaming more fun, that they would like to see more simulations added into their courses, and that the simulation under consideration helped to increase their confidence in their own decision making skills.

Students responded that they liked the competitive nat ure of the simulation, and analysis of student performance data shows that the participants performed successfully in the simulation besting teams from top tier academic institutions and Fort une 500 Companies. It is believed that the positive comparat ive performance helps to increase the confidence of students who are otherwise availed few opportunities to interact with, let alone compete against, corporate executives and students from top ranked majority inst it utions. Furthermore, simulation performance provides students with tangible evidence of their business acumen which can be shared with prospective employers. 
The data gathered in this study does allow the authors to postulate, based on the strong levels of student satisfaction as well as the high success rates of this student population, which traditionally underperforms in more traditional mode of assessments, that competitive web-based simulations enhance the overall learning experiences of minority students enrolled in higher education business programs and may serve as an educational equalizer.

The findings of this study have encouraged the University of Maryland Eastern Shore to further embrace competitive web-based simulations in its curriculum. To further student assessment a standardized and validated examination that is directly aligned to concepts taught and applied in both the course and the simulation has been implemented. Student performance data on the examination is being collected and will be analyzed and compared to student simulation performance and participation. Additionally, the process diaries completed by students are being strengthened and the information collected. Finally, a new peer review rubric is being introduced to be used by students in order to encourage greater self and peer performance assessment.

\section{References}

Arias-Aranda, D. (2007). Simulating reality for teaching strategic manag ement. Innovations in Education and Teaching International, 44(3), 273-286. Retrieved September 4, 2008, from ProQuest Education Journals database. (Document ID: 1331116841).

Astleitner, H. (2002). Teaching critical thinking on-line. Journal of Instructional Psychology. 29(2), 53-77.

Bennett, R. E. (2002). Inexorable and inevitable: The continuing story of technology and assessment. Journal of Technology, Learning, and Assessment, 1(1). Available at http://www.jtla.org

Berge, Z. L. (2002). Active, interactive and reflective eLearning. Quarterly Review of Distance Education. 3(2), 181-190.

Buzzetto-More, N. (2008, April). Exploring the second self in Second Life. USM Symposium on Online Resources and Pedagogy for Teacher Education. Adelphia, Maryland.

Buzzetto-More, N., \& Ukoha, O. (2009). Student satisfaction with web based mathematics instruction. Global Digital Business Review. Proceedings of the Global Digital Business Association Conference, October 15-17, 2008, Washington, D.C.

Buzzetto-More, N., Werner, N., \& Martinez, G. (2008, April). Teaching effectively through simulations. 2008 Maryland Business Education Association Conference. Ocean City, MD.

Cherry, G. (1999). Simulations for lifelong learning. Proceedings of the National Education Computing Conference. Atlantic City, NJ June 22-23, 1999, pp. 2-11.

Drago, W. (2004, July 23). Study: Virtual courses producing measurable gains in high-level learning. Ascribe. Retrieved 2/12/06 from http://www. ascribe. org/cgibin/spew4th.pl? ascribeid $=20040723.102807 \&$ time $=10 \% 2050 \%$.

Harvard Business School Publishing. (2008). Harvard business school publishing releases first online simulation. Education Business Weekly. 38. Retrieved September 4, 2008, from ProQuest Education Journals database. (Document ID: 1529134221).

Kerka, S. (2001). Capstone experiences in career and technical education. Practice Application Brief No 16, Clearing house on Adult, Career, and Vocational Education. Retrieved November, 2003, from http://ericacve. org/docs/pab00025.pdf

Kolb, D. A. (1984). Experiential learning. Experience as the source of learning and development. Englewood Cliffs, New Jersey: Prentice Hall.

Lainema, T., \& Lainema, K. (2007). Advancing acquisition of business know-how. Journal of Research on Technology in Education, 40(2), 183-198. 
Lainema, T., \& Nurmi, S. (2006). Applying an authentic, dynamic learning environment in real world business. Computers and Education, 47(1), 94-115.

Limniou, M., Roberts, D., \& Papadopoulos, N. (2008). Full immersive virtual environment cave[TM] in chemistry education. Computers \& Education, 51(2), 54-84.

MacKay, R. B., \& McKiernan, P. (2004). Exploring strategy context with foresight. European Management Review, 1(1), 69-77.

Mankins, M. C. (2004). Stop wasting valuable time. Harvard Business Review, 82(9), 58-65.

Mitchell, B. (2004). Combining cases and computer simulations in strategic management courses. Journal of Education for Business, 79(4), 198-204.

Northeastern University College of Business Administration completes its undergraduate business experience with BTS simulation. (2008). Education Business Weekly, 12. Retrieved September 4, 2008, from ProQuest Education Journals database. (Document ID: 1534810111).

Page. D. (2006). 25 tools, technologies, and best practices. T. H. E. Journal, 33 (8). Retrieved from http://thejournal.com/articles/18042

Salaway, G., Katz, R., \& Caruso, J. (2006). The study of undergraduate students and information technology. EDUCAUSE Center for Applied Research, 7. Retrieved from www.educause.edu/ecar/

Siddiqui, A., Khan, M., \& Akhtar, S. (2008). Supply chain simulator: A scenario-based educational tool to enhance student learning. Computers \& Education, 51(1), 252. (ERIC Document Reproduction Service No. EJ794656) Retrieved September 4, 2008, from ERIC database.

Wall, J., \& Ahmed, V. (2008). Use of a simulation game in delivering blended lifelong learning in the construction industry--Opportunities and challenges. Computers \& Education, 50(4), 1383. (ERIC Document Reproduction Service No. EJ790946) Retrieved September 4, 2008, from ERIC database.

Wiggins, G. (1990). The case for authentic assessment. Practical Assessment Research and Evaluation, 2(2).

Willie, C. V., Reddick, R. J., \& Brown, R. (2005). The black college mystique. Lanham, MD: Rowman \& Littlefield.

\section{Biographies}

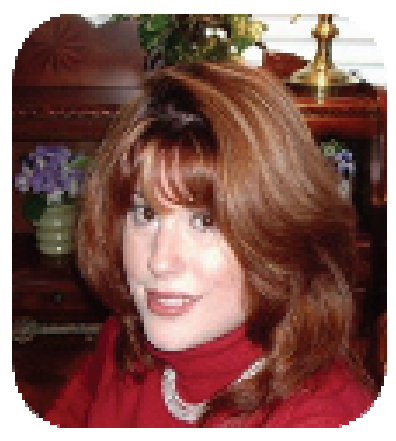

Dr. Ni cole A. Buzze tto-More is an Associate Professor in the Department of Business at the University of Maryland Eastern Shore. She is also Co-Founder of the UMES Office of Instructional T echnology. She received her doctorate in communication and instructional technology from Columbia University. She has served as the edit or of two e-learning books published in 2007 , has contributed several book chapters, is on the editorial board of a number of journals, has authored numerous publications in referred journals, and has been recognized with awards from the American Distance Education Consortium, Global Digital Business Association, and the Informing Science Institute. She is currently preparing her third book to be released in 2010 by the Informing Science Press. 


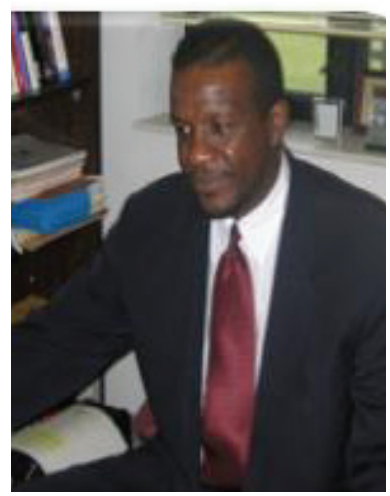

Dr. Bryant C. Mitchell is an Associate Professor of Management in the Department of Business, at the University of Maryland Eastern Shore. He received a Ph.D. in Industrial Management from Clemson University in 2001, was awarded a MBA in Finance from Columbia University Graduate School of Business, and earned his undergraduate degree from the University of Maryland Eastern Shore. Dr. Mitchell's research interests include: improving retention and graduation rates among underrepresented minorities and micro-business entrepreneurship and strat egy. He serves of the edit orial board of the Journal of Business and Leadership. 